\title{
The effect of intravitreal bevacizumab on ocular blood flow in diabetic retinopathy and branch retinal vein occlusion as measured by laser speckle flowgraphy
}

\author{
This article was published in the following Dove Press journal: \\ Clinical Ophthalmology \\ II June 2014 \\ Number of times this article has been viewed
}

\author{
Fumihiko Nitta' \\ Hiroshi Kunikata ${ }^{1,2}$ \\ Naoko Aizawa' \\ Kazuko Omodaka' \\ Yukihiro Shiga' \\ Masayuki Yasuda' \\ Toru Nakazawa ${ }^{1-3}$ \\ 'Department of Ophthalmology, \\ Tohoku University Graduate School of \\ Medicine, Sendai, Japan; ${ }^{2}$ Department \\ of Retinal Disease Control, Tohoku \\ University Graduate School of \\ Medicine, Sendai, Japan; ${ }^{3}$ Department \\ of Advanced Ophthalmic Medicine, \\ Tohoku University Graduate School \\ of Medicine, Sendai, Japan
}

\begin{abstract}
Background: This study evaluated the effect of intravitreal injection of bevacizumab (IVB) on macular edema associated with diabetic retinopathy (DME) or branch retinal vein occlusion (BRVOME) using laser speckle flowgraphy.

Methods: A comparative interventional study of 25 eyes from 22 patients with macular edema (DME group: 12 eyes; BRVOME group: 13 eyes) who underwent IVB. Mean blur rate (MBR) was measured in the retinal artery, retinal vein, optic nerve head $(\mathrm{ONH})$, and choroid before and after IVB.
\end{abstract}

Results: In the BRVOME group, there was no significant change in MBR in the retinal artery, retinal vein or $\mathrm{ONH}$, but choroidal MBR decreased significantly $(P=0.04)$. In the DME group, the MBR in the retinal artery, retinal vein, $\mathrm{ONH}$, and choroid decreased significantly $(P=0.02$, $P=0.04, P<0.001$, and $P=0.04$, respectively). In the DME group, pre-IVB MBR in the ONH was significantly correlated with post-IVB foveal thickness $(R=-0.71, P=0.002)$. There was no such correlation in the BRVOME group in the ONH.

Conclusion: IVB had a suppressive effect on circulation in eyes with DME but not in those with BRVOME. This suggests that this noninvasive and objective biomarker may be a useful part of pre-IVB evaluations and decision-making in DME.

Keywords: macular edema, mean blur rate, optic nerve head, biomarker, ocular circulation

\section{Introduction}

Macular edema is one of the main causes of reduced vision in various retinal diseases, including diabetic retinopathy (DR) and branch retinal vein occlusion (BRVO). ${ }^{1-4}$ This condition is difficult to treat successfully, even for experienced ophthalmologists. Currently, intravitreal injection of bevacizumab (IVB), an anti-vascular endothelial growth factor (VEGF) antibody, is one of the most accepted treatments. ${ }^{5-8}$ It can improve vision by temporarily blocking VEGF action and subsequently reducing macular edema. However, in cases of DR- or BRVO-associated macular edema (DME and BRVOME, respectively), the effect of IVB is often insufficient, requiring the treatment to be repeated many times. ${ }^{8-11}$ It is not known why the effectiveness of the treatment is poor in these cases, as the underlying mechanism of IVB's ability to reduce macular edema is still not well understood. Furthermore, the effect of IVB on retinal circulation is also unknown, although there are a few reports that IVB causes a decrease in intraocular and systemic circulation. ${ }^{12,13}$ Particularly, IVB can adversely affect the visual prognosis of patients with central retinal vein occlusion and underlying systemic diseases such as diabetes, or ischemic heart or cerebrovascular diseases. ${ }^{14,15}$
Correspondence: Hiroshi Kunikata Department of Ophthalmology, Tohoku University Graduate School of Medicine, I-I Seiryo-machi, Aoba-ku, Sendai 980-8574, Japan $\mathrm{Tel}+8 \mathrm{I} 227177294$

Fax +8I 227177298

Email kunikata@oph.med.tohoku.ac.jp (c) 2014 Nitta et al. This work is published by Dove Medical Press Limited, and licensed under Creative Commons Attribution - Non Commercial (unported, v3.0)
LY 20 ) Dove Medical Press Limited, provided the work is properly attributed. Permissions beyond the scope of the License are administered by Dove Medical Press Limited. Information on how to request permission may be found at: http://www.dovepress.com/permissions.php 
Ischemic change after any medical intervention is ordinarily evaluated with fluorescein angiography, but this technique is invasive, can cause severe complications, including anaphylactic shock, and its results can be affected by time-dependent changes after injection. Recent innovations in an alternative technique, laser speckle flowgraphy (LSFG), have allowed us to quickly and easily monitor changes in tissue circulation over time. ${ }^{16,17}$ The main measurement parameter of LSFG, mean blur rate (MBR), is an automatically calculated index of ocular blood flow derived from the scatter pattern produced when the ocular fundus is irradiated with laser light. MBR represents the velocity of the blurring in the speckle pattern that is caused by blood flow. Measured values of MBR correlate well with absolute blood flow values measured with the hydrogen gas clearance and microsphere methods. ${ }^{18,19}$ Previous reports have shown that despite being a relative value, MBR can be considered an accurate representation of both ocular blood flow and velocity. ${ }^{20,21}$ The quality of LSFG measurements mainly relies on the clarity of the ocular media, but LSFG has already contributed to many recent findings in glaucoma research, and is especially useful in examining the relationship between glaucoma and ocular circulation. ${ }^{16,22-25}$

In this study, we hypothesized that IVB had a different effect on ocular blood circulation in DME and BRVOME. We evaluated the association between MBR and clinical findings in post-IVB eyes in order to reveal the different pathogenesis of DME and BRVOME, and to find new biomarkers of postIVB visual prognosis. Thus, our purpose was to evaluate the effect of IVB in DME and BRVOME patients by examining the association of MBR and clinical findings related to the structure and function of the retina.

\section{Materials and methods Setting and design}

This was an institutional, prospective, nonrandomized, interventional case series. Subjects were recruited from patients referred to the Retina Service of Tohoku University Hospital. Intravitreal intervention and follow-up were both performed at this clinic.

\section{Patients}

The study comprised 25 eyes of 22 patients (eleven men and eleven women, mean age: 67.5 years) with retinal disease (DR group: 12 eyes of nine patients with DR; BRVO group: 13 eyes of 13 patients with BRVO) and macular edema.
Each patient provided informed consent for their participation in this study as well as for the treatments they received. The study was approved by the institutional review board of Tohoku University Graduate School of Medicine (Protocol No 2013-164; May 17, 2013). The research was conducted according to the provisions of the Declaration of Helsinki, 1995 (as revised in Edinburgh, 2000). ${ }^{26,27}$

\section{Intervention}

In all eyes, after instillation of topical anesthetic $(0.4 \%$ oxybuprocaine hydrochloride; Benoxil), sterilization of the eyelid (10\% povidone-iodine Swabstick), and instillation of $1.25 \%$ povidone-iodine (Isodine), $1.25 \mathrm{mg} / 0.05 \mathrm{~mL}$ of bevacizumab (Avastin) was injected into the vitreous cavity with a standard pars plana approach $(3.5 \mathrm{~mm}$ posterior to the limbus) using a 30 -gauge needle.

\section{Measurement of clinical findings}

We measured best-corrected visual acuity (BCVA) before, 1 week after, and 1 month after IVB. Similarly, we measured foveal thickness (FT) before, 1 week after, and 1 month after IVB. BCVA was measured with a logMAR chart (5 m) (LVC-10; NEITZ Instruments, Tokyo, Japan), and retinal thickness was measured with optical coherence tomography (OCT) (OCT3000; Carl Zeiss Meditec AG, Jena, Germany). The retinal thickness of the central fovea was defined as the distance between the inner limiting membrane and the retinal pigment epithelium, and was automatically calculated by the OCT3000 software. A macular thickness map was made with the OCT retinal mapping program from six radial scans intersecting at the fovea. The mean retinal thickness was calculated in nine regions: the $1,000 \mu \mathrm{m}$ central area and the four quadrants of the inner and outer rings. FT was defined as the value of the $1,000 \mu \mathrm{m}$ central area. Blood pressure and intraocular pressure (IOP) were measured after 10 minutes of rest.

\section{Measurement using laser speckle flowgraphy}

We measured MBR with the LSFG NAVI system (Softcare Co., Ltd., Fukutsu, Japan) before, 1 week after, and 1 month after IVB. The measurement conditions were kept constant as follows: angle of view, $21^{\circ}$; number of pixels measured, $750 \times 360$; and laser power, $1.37 \mathrm{~mW}$. Determination of MBR was made with LSFG Analyzer software (version 3.0.47.0; Softcare Co., Fukutsu, Japan). We measured four regions: a selected retinal artery, a selected retinal vein, the optic nerve head $(\mathrm{ONH})$, and the choroid. Measurements for the retinal artery and the retinal vein were taken from sites near the $\mathrm{ONH}$ (within 1.5 papilla 
diameters). In patients with BRVOME, blood vessels in the quadrant containing the obstruction were not selected in order to avoid the influence of the hemorrhage. The mean number of samples was 1,013, 1,482.3, and 47,785.2 in the retinal artery, the retinal vein, and the $\mathrm{ONH}$, respectively. Measurement of the choroid was performed in a square area ( $150 \times 150$ pixels; 19,479 samples) not containing retinal blood vessels, in a temporal location located one papilla diameter away from the ONH. Only a single measurement of each region was performed.

\section{Statistical analysis}

Analysis was done with Ekuseru-Toukei 2006 software (Social Survey Research Information Co., Ltd., Tokyo, Japan). The data are presented as mean \pm standard deviation. The significance of the difference between pre- and postIVB data was assessed with the Friedman test and Scheffe's paired comparison. We also used the Mann-Whitney $U$ test to compare characteristics other than sex and optic media and clinical findings before and after IVB in the BRVO and DR groups. Sex and optic media were compared with Fisher's exact test. The Spearman correlation coefficient was used to determine the relationship between MBR and FT in the ONH. A $P$-value of less than 0.05 was considered to be statistically significant.

\section{Results}

A comparison of characteristics and findings before and after IVB in the BRVOME and DME groups is shown in Table 1. Before IVB, there were no significant differences in age, optic media, IOP, or FT between the two groups, but there were significant differences in sex distribution and visual acuity. After IVB, there was no difference in IOP between the two groups, but there was a significant difference in FT. FT in the BRVOME group was significantly lower than in the DME group 1 month post-IVB.

BCVA and FT before and after IVB are shown in Figures 1 and 2, respectively. MBR in the retinal artery, retinal vein, $\mathrm{ONH}$, and choroid before and after IVB is shown in Figure 3. In the DME group, MBR changed significantly in all regions 1 week and 1 month after IVB (retinal artery, $P=0.02$; retinal vein, $P=0.04$; ONH, $P<0.001$; and choroid, $P=0.04)$. In the BRVOME group, MBR did not change significantly 1 week or 1 month after IVB in any of the measured regions (retinal artery, $P=0.09$; retinal vein, $P=0.33$; $\mathrm{ONH}$, $P=0.50)$, except the choroid $(P=0.04)$.

The relationship between FT and MBR in the ONH of the DME group is shown in Figure 4. Pre-IVB MBR in the
Table I Comparison of characteristics and findings before and after intravitreal injection of bevacizumab in groups with branch retinal vein occlusion and diabetic retinopathy

\begin{tabular}{|c|c|c|c|}
\hline Group & BRVOME & DME & $P$-value \\
\hline Number of eyes & 13 & 12 & \\
\hline Age & $71.0 \pm 9.6$ & $63.8 \pm 9.2$ & $0.0565^{\mathrm{a}}$ \\
\hline $\operatorname{Sex}(M: F)$ & $(4: 9)$ & $(7: 2)$ & $* 0.0402^{\mathrm{b}}$ \\
\hline Optic media & $(I I: I)$ & $(10: 3)$ & $0.3278^{b}$ \\
\hline \multicolumn{4}{|l|}{ (lens: pseudophakia) } \\
\hline \multicolumn{4}{|l|}{ BCVA (logMAR) } \\
\hline Pre-IVB & $0.8 \pm 0.26$ & $0.4 I \pm 0.2 I$ & $* * 0.0016^{a}$ \\
\hline I week post-IVB & $0.64 \pm 0.4$ & $0.49 \pm 0.23$ & $0.3355^{a}$ \\
\hline I month post-IVB & $0.64 \pm 0.33$ & $0.45 \pm 0.29$ & $0.1245^{a}$ \\
\hline \multicolumn{4}{|l|}{ IOP (mmHg) } \\
\hline Pre-IVB & $13.6 \pm 2.4$ & $12.8 \pm 1.5$ & $0.2409^{a}$ \\
\hline I week post-IVB & $12.1 \pm 2.3$ & $13.4 \pm 2.3$ & $0.1818^{a}$ \\
\hline I month post-IVB & $12.9 \pm 2.1$ & $12.6 \pm 2.2$ & $0.8062^{\mathrm{a}}$ \\
\hline \multicolumn{4}{|l|}{ Foveal thickness $(\mu \mathrm{m})$} \\
\hline Pre-IVB & $549.8 \pm 127.7$ & $465.7 \pm 120.1$ & $0.0727^{\mathrm{a}}$ \\
\hline I week post-IVB & $327.5 \pm 110.1$ & $396.8 \pm 116.1$ & $0.2108^{a}$ \\
\hline I month post-IVB & $270.2 \pm 67.9$ & $408.3 \pm 148.6$ & $* * 0.0036^{a}$ \\
\hline
\end{tabular}

Notes: a Mann-Whitney $U$ test; ' ${ }^{\circ}$ Fisher's exact test. ${ }^{*} P<0.05$; ${ }^{* *} P<0.01$.

Abbreviations: BCVA, best-corrected visual acuity; BRVOME, branch retinal vein occlusion-associated macular edema; DME, diabetic macular edema; IOP, intraocular pressure; IVB, intravitreal bevacizumab; logMAR, logarithm of the minimum angle resolution; $M$, male; $F$, female.

ONH was not correlated with pre-IVB FT $(P=0.33)$, but post-IVB MBR in the ONH was correlated with post-IVB FT $(R=-0.80, P=0.009)$. Furthermore, pre-IVB MBR in the ONH was correlated with post-IVB FT $(R=-0.71, P=0.002)$. The relationship between FT and MBR in the $\mathrm{ONH}$ of the BRVOME group is shown in Figure 5. There were no equivalent correlations in the ONH of the BRVOME group.

Representative eyes with DME and BRVOME are shown in Figures 6 and 7, respectively.

Complications arising from IVB, such as endophthalmitis, ocular hypertension, retinal detachment, and vitreous hemorrhage, did not occur in any of the patients in this study.

\section{Discussion}

We set out to investigate the effect of IVB on the retina in DME and BRVOME patients, in particular its effect on ocular blood flow. We found that in BRVOME patients, there was no significant change in MBR in any of the areas measured in this study, with the exception of a significant decrease in the choroid. In the group of patients with DME, there was a significant decrease in MBR in all measured areas. Interestingly, however, we observed that pre-IVB MBR in the DME patients was significantly correlated with post-IVB FT; specifically, higher MBR before IVB was correlated with lower FT after IVB. 


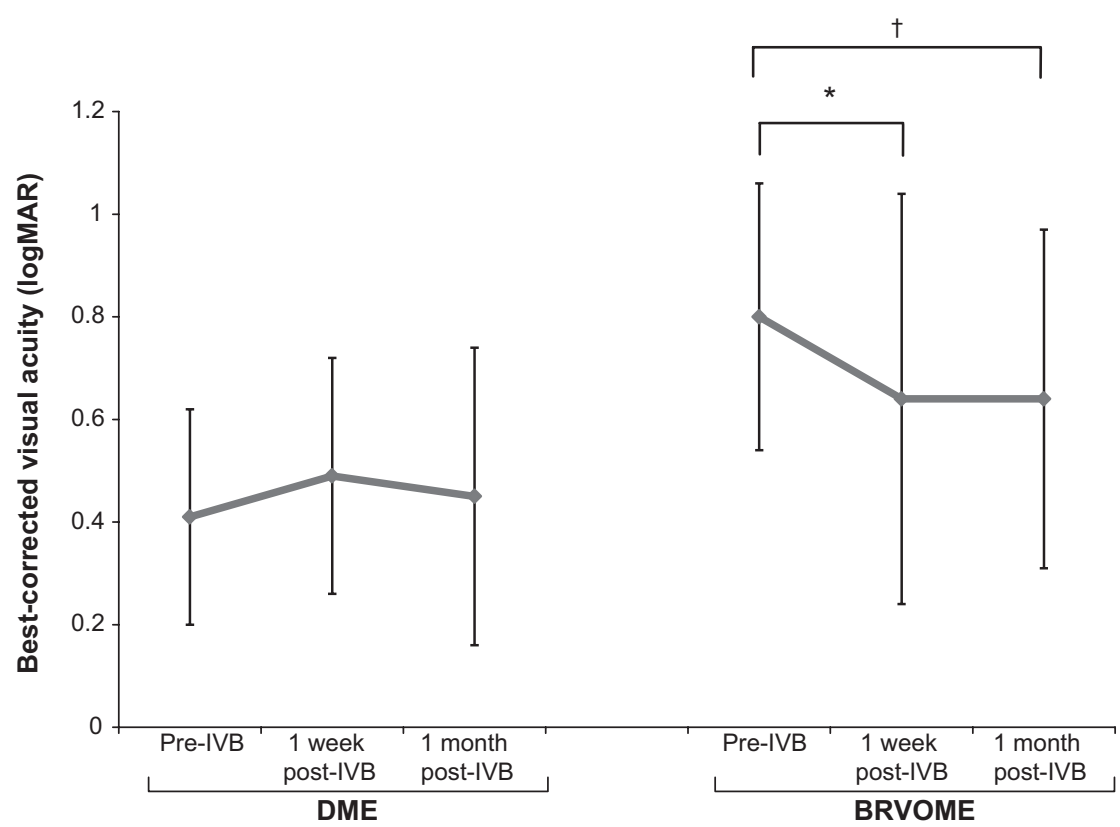

Figure I Best-corrected visual acuity before and after intravitreal injection of bevacizumab.

Notes: BCVA did not change significantly after I week or I month in the DME group $(P=0.34)$ but did in the BRVOME group ( $P=0.049)$, with the most significant improvement being I week after IVB $(P=0.03)$; Freidman test compared between three points pre-IVB, I week post-IVB, I month post-IVB; ${ }^{\dagger} P<0.05$, Scheffe’s paired comparison compares between groups, $* P<0.05$.

Abbreviations: BCVA, best-corrected visual acuity; BRVOME, branch retinal vein occlusion-associated macular edema; DME, diabetic macular edema; IVB, intravitreal bevacizumab; logMAR, logarithm of the minimum angle resolution.

There are no reports on the influence of IVB on intraocular microcirculation predating the current study. Our study, in which we analyzed the results of only a single injection, broadly agrees with existing reports showing that IVB leads to a significant improvement in FT and BCVA in patients with BRVOME ${ }^{5,9}$ Some earlier papers also found a similar improvement in patients with DME, ${ }^{28-30}$ but our study contradicts such

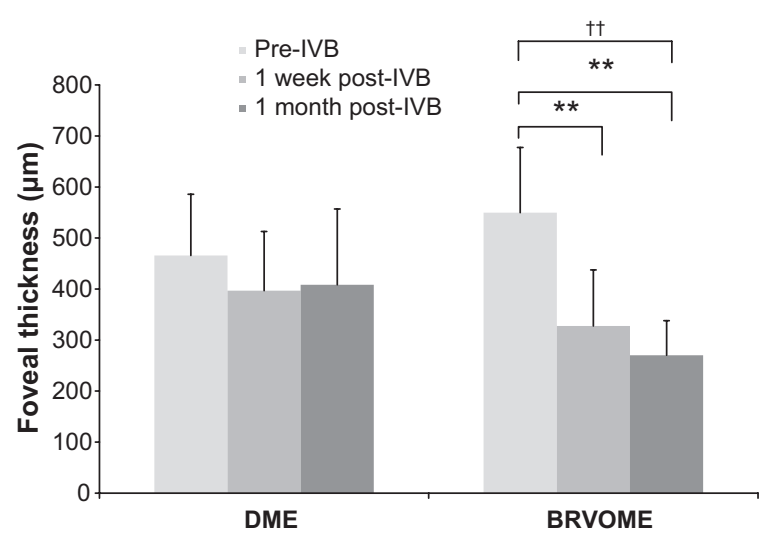

Figure 2 Foveal thickness before and after intravitreal injection of bevacizumab. Notes: FT did not change significantly I week or I month after IVB in the DME group $(P=0.20)$, but did in the BRVOME group $(P<0.00 \mathrm{I})$. FT improved in patients with BRVOME both I week and I month after IVB $(P=0.007$ and $P<0.00$ I, respectively); Friedman test compared between three points pre-IVB, I week postIVB, I month post-IVB; ${ }^{\dagger \dagger} P<0.01$; Scheffe's paired comparison compared between groups, ${ }^{* * P}<0.01$.

Abbreviations: BRVOME, branch retinal vein occlusion-associated macular edema; DME, diabetic macular edema; FT, foveal thickness; IVB, intravitreal bevacizumab. findings. The exact reason for this discrepancy is unclear, but it may be related to differences in injection times and follow-up periods, pre-IVB BCVA, differences in the demographics of the DME patients, or the small number of participants in this study. One of the most interesting findings of this study, that IVB reduces MBR in all regions of the eye in patients with DME, has not been previously reported. Previous reports on post-IVB ocular circulation used color Doppler imaging (CDI) and found that blood flow decreased after IVB in the ophthalmic artery, the posterior ciliary artery, and the central retinal artery. ${ }^{12,31}$ These studies were unable to report on blood flow within the eye itself, however, as the intraocular vessels are too small to allow CDI to function. Access to LSFG was therefore a major advantage of this study since it allowed us to directly measure MBR in the retinal vessel, $\mathrm{ONH}$, and choroid and confirm the reduction of ocular blood flow in eyes with DME. We also observed a decrease in choroidal MBR in the BRVOME group, most likely because, as shown in previous reports, ${ }^{32,33}$ the choroid lacks an autoregulation system and is easily affected by exercise. Our findings for the choroid were based on measurements taken of the MBR in retinal regions lacking large vessels, in accord with established practice for LSFG measurement of the choroid. ${ }^{34}$

Another interesting finding of our study was that the lack of structural improvement in the DME patients may have been related to the decrease in MBR in the $\mathrm{ONH}$ observed before 


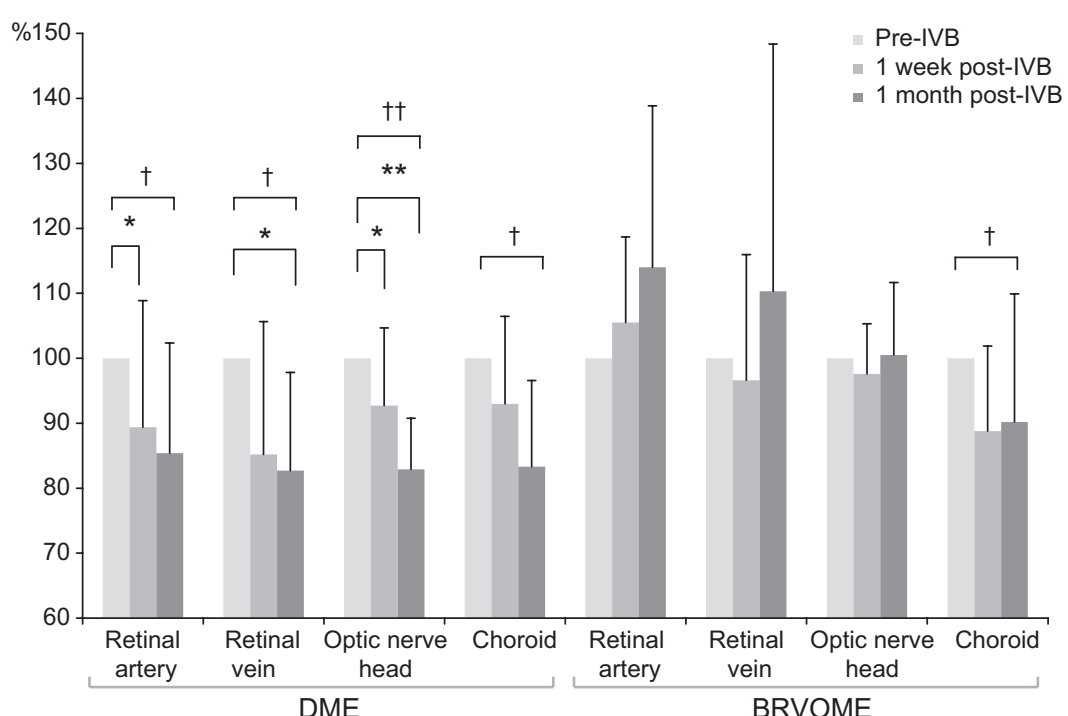

Figure 3 Mean blur rate in the retinal artery, retinal vein, optic nerve head, and choroid before and after intravitreal injection of bevacizumab.

Notes: In patients with DME, a comparison of MBR values before, I week after, and I month after IVB revealed significant changes in all measured regions (retinal artery, $P=0.02$; retinal vein, $P=0.04$; ONH, $P<0.00 \mathrm{I}$; and choroid, $P=0.04)$. MBR after I week fell significantly in the retinal artery by $10.6 \%(P=0.03)$ and in the $O N H$ by $7.27 \%$ $(P=0.049)$. MBR after I week also fell by $14.8 \%(P=0.19)$ in the retinal vein and by $6.97 \%(P=0.15)$ in the choroid, but these differences were not significant. MBR after I month fell significantly in the retinal vein by $17.3 \%(P=0.049)$ and in the ONH by $17.1 \%(P<0.001)$. MBR after I month also fell by $14.7 \%$ in the retinal artery $(P=0.08)$ and $16.7 \%$ in the choroid $(P=0.06)$, but these differences were not significant. In patients with BRVOME, a comparison of MBR values before, I week after, and I month after IVB revealed a significant change only in the choroid $(P=0.04)$. Significant changes in MBR were not observed in the retinal artery $(P=0.09)$, retinal vein $(P=0.33)$, or the $O N H(P=0.50)$. Significant changes in blood flow were not found after I week in any of the measured regions (retinal artery, $P=0.39 ;$ retinal vein, $P=0.84 ; O N H, P=0.50 ;$ and choroid, $P=0.09$ ). Furthermore, significant changes were not found in blood flow after I month in any of the measured regions (retinal artery, $P=0$. I0; retinal vein, $P=0.67 ; O N H, P=0.84$; and choroid, $P=0.07$ ). Finally, significant changes were not found when comparing blood flow I week and I month after IVB in any of the regions (retinal artery, $P=0.73$; retinal vein, $P=0.33$; $O N H, P=0.84$; and choroid, $P=I .00$ ); Friedman test compared between points pre-IVB, I week post-IVB, I month post-IVB; ${ }^{+} P<0.05$, ${ }^{\dagger} P<0.0 \mathrm{I}$; $S$ cheffe's paired comparison compares between groups, $* P<0.05$, $* * P<0.0$ I.

Abbreviations: BRVOME, branch retinal vein occlusion-associated macular edema; DME, diabetic macular edema; IVB, intravitreal bevacizumab; MBR, mean blur rate; $\mathrm{ONH}$, optic nerve head.
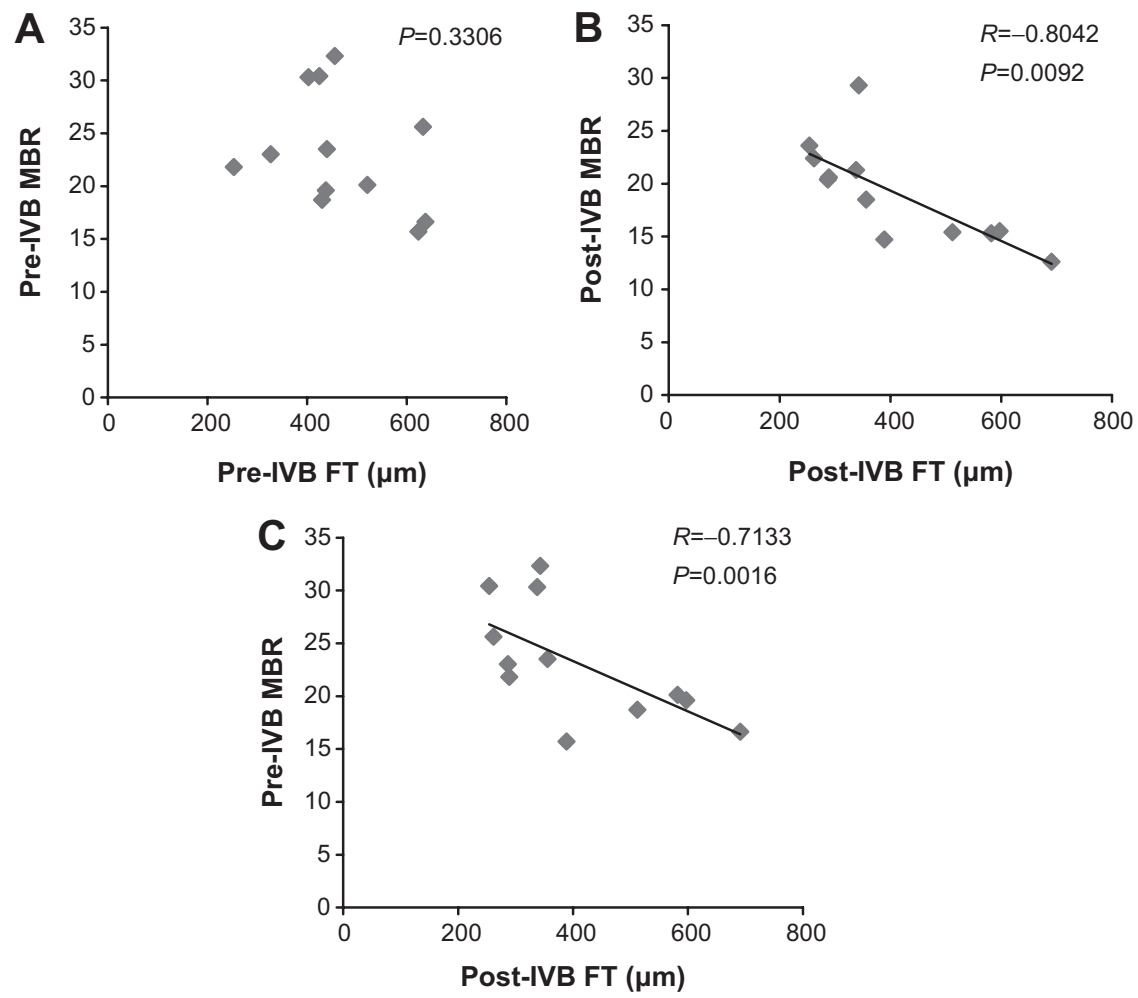

Figure 4 Relationship between foveal thickness and mean blur rate in eyes with diabetic macular edema.

Notes: Pre-IVB MBR was not correlated with pre-IVB FT $(P=0.33)(\mathbf{A})$. However, post-IVB MBR was correlated with post-IVB FT $(R=-0.80, P=0.0 \mathrm{I})(\mathbf{B})$. Furthermore, pre-IVB MBR was correlated with post-IVB FT $(R=-0.7 \mathrm{I}, P=0.002)(\mathrm{C})$. One MBR sample is represented by one pixel.

Abbreviations: FT, foveal thickness; IVB, intravitreal bevacizumab; MBR, mean blur rate. 

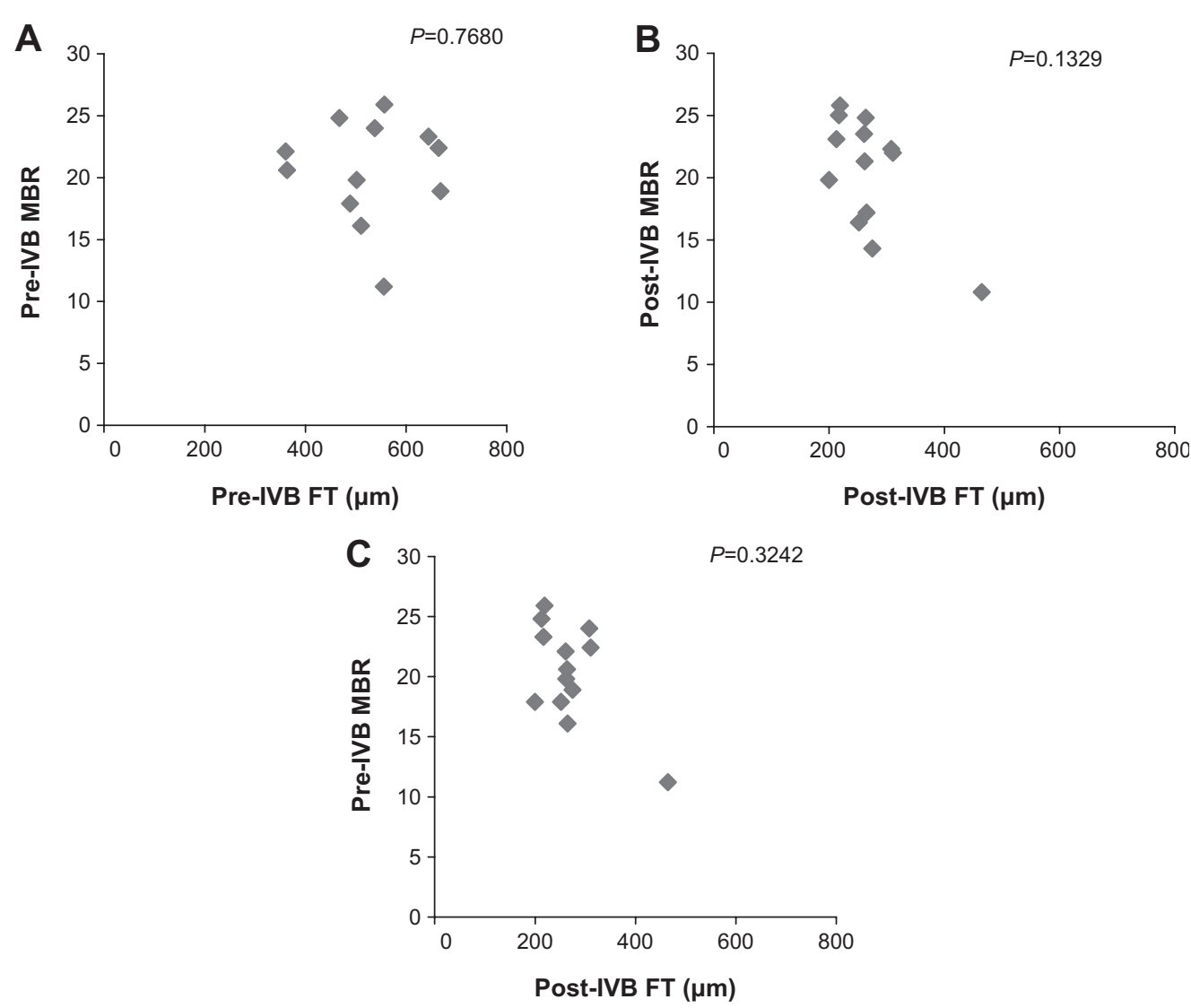

Figure 5 Relationship between foveal thickness and mean blur rate in eyes with branch retinal vein occlusion-associated macular edema.

Notes: Pre-IVB MBR was not correlated with pre-IVB FT $(P=0.77)(\mathbf{A})$, nor was post-IVB MBR correlated with post-IVB FT ( $P=0.13)(\mathbf{B})$. In addition, pre-IVB MBR was not correlated with post-IVB FT $(P=0.32)(C)$. One MBR sample is represented by one pixel.

Abbreviations: FT, foveal thickness; IVB, intravitreal bevacizumab; MBR, mean blur rate.
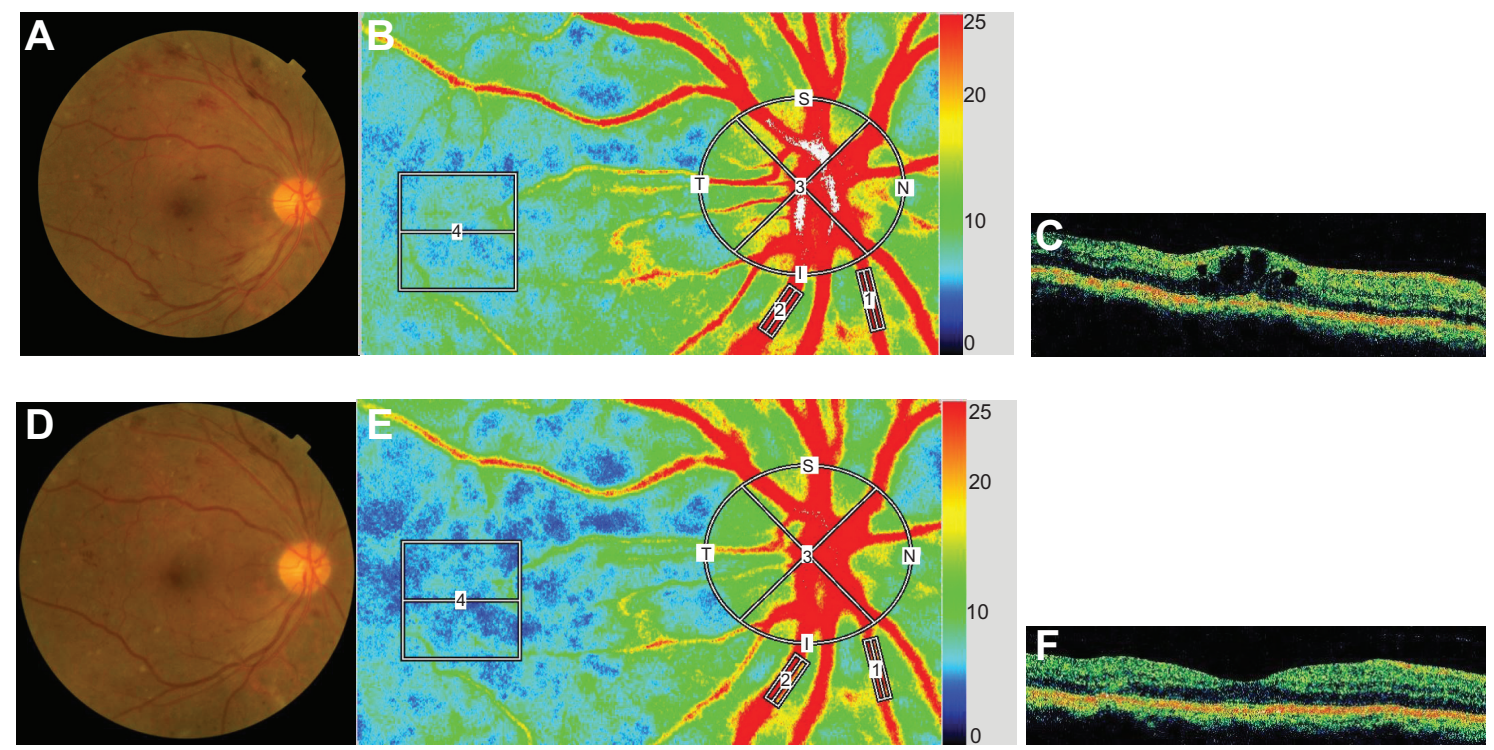

Figure 6 Representative eye with diabetic macular edema.

Notes: Images from a 59-year-old man with DME in his right eye; Fundus color photographs (A and D), color LSFG maps (B and E), and axial OCT images at fovea (C and F) are shown. Pre-IVB findings are above (A, B, and $\mathbf{C}$ ) and findings I month after IVB are below (D, E, and F). In the color LSFG maps (B and E), the numbers I and 2 indicate the rectangular scanning areas for the retinal artery and vein, respectively; 3 and 4 indicate the circular and square scanning areas for the optic nerve head and choroid, respectively. Pre-IVB MBR was 30.1 in the retinal artery, 43.6 in the retinal vein, 31.0 in the optic nerve head, and 7.0 in the choroid. MBR I month after IVB was 22.6 (24.9\% decrease) in the retinal artery, 30.3 (30.5\% decrease) in the retinal vein, 24.2 (21.9\% decrease) in the optic nerve head, and 5.8 (I7.1\% decrease) in the choroid. Decimal bestcorrected visual acuity in the right eye was 0.3 before IVB and did not change I month after IVB. FT in the right eye was $425 \mu \mathrm{m}$ before IVB and $272 \mu \mathrm{m}$ I month after IVB. Abbreviations: DME, diabetic macular edema; FT, foveal thickness; IVB, intravitreal bevacizumab; LSFG, laser speckle flowgraphy; MBR, mean blur rate; OCT, optical coherence tomography. 

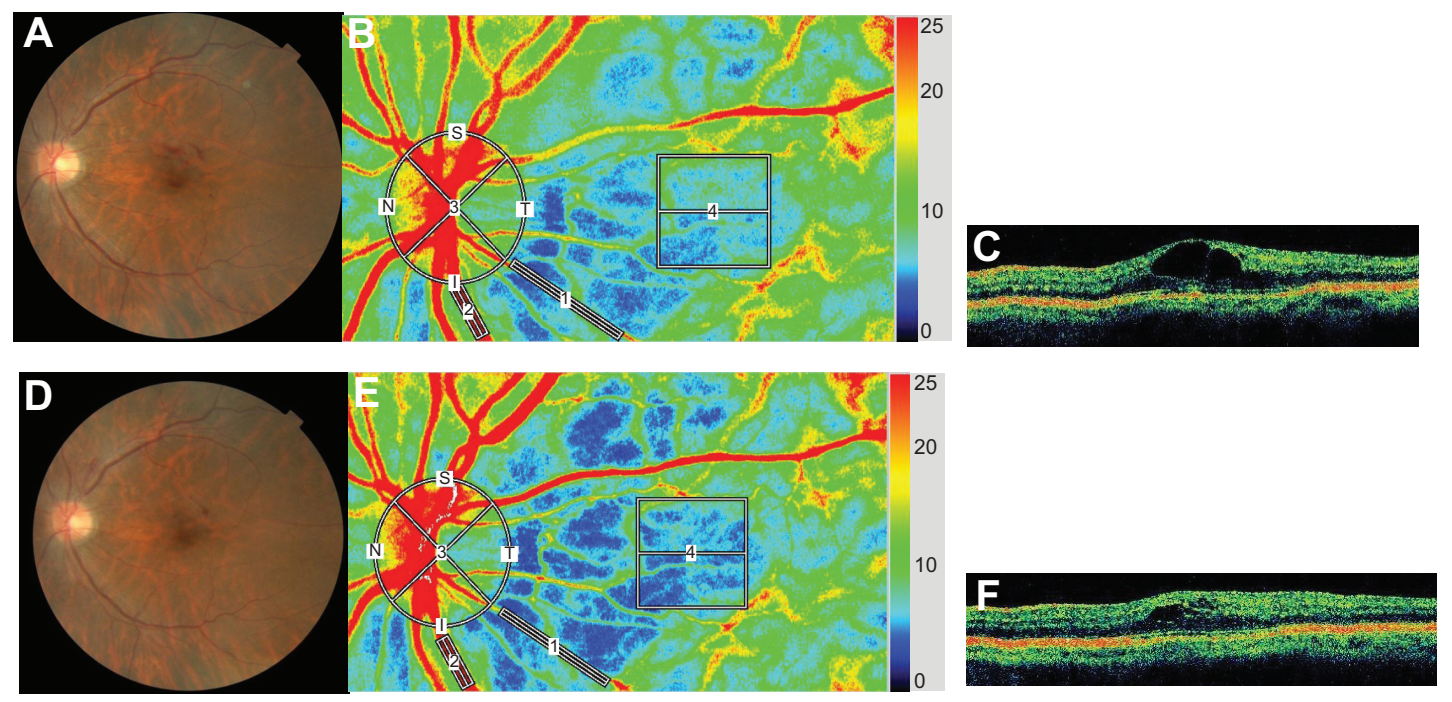

Figure 7 Representative eye with branch retinal vein occlusion-associated macular edema.

Notes: Images from a 65-year-old woman with BRVOME in her left eye. Fundus color photographs (A and D), color LSFG maps (B and E), and axial OCT images at fovea ( $\mathbf{C}$ and $\mathbf{F}$ ) are shown. Pre-IVB findings are above (A, B, and $\mathbf{C}$ ) and findings I month after IVB are below (D, E, and F). In the color LSFG maps (B and E), the numbers $\mathrm{I}$ and 2 indicate the rectangular scanning areas for the retinal artery and vein, respectively; 3 and 4 indicate the circular and square scanning areas for the optic nerve head and choroid, respectively. Pre-IVB MBR was 15.9 in the retinal artery, 35.7 in the retinal vein, 23.5 in the optic nerve head, and 7.2 in the choroid. MBR I month after IVB was I4.0 (I 2.0\% decrease) in the retinal artery, 33.4 (6.4\% decrease) in the retinal vein, 26.0 (I0.6\% increase) in the optic nerve head, and 6.2 (I3.9\% decrease) in the choroid. Decimal best-corrected visual acuity in the right eye was 0.5 before IVB and did not change after I month. FT in the right eye was $364 \mu \mathrm{m}$ before IVB and $264 \mu \mathrm{m}$ I month after IVB. Abbreviations: BRVOME, branch retinal vein occlusion-associated macular edema; FT, foveal thickness; IVB, intravitreal bevacizumab; LSFG, laser speckle flowgraphy; MBR, mean blur rate; OCT, optical coherence tomography.

IVB and 1 month after IVB. We observed no such association in the BRVO group. This is an interesting discrepancy that may be related to the pathogenesis of each type of macular edema. However, it should be noted that the characteristics of the two groups in our study did not match perfectly, differing in sex distribution and pre-IVB BCVA. From these results, however, we believe that it is fair to speculate that the effect of bevacizumab on intraocular tissues changes in the presence of systemic diseases such as diabetes. In our study, the eyes with DME probably experienced the effects of excessive VEGF over the entire retina, while the effects were limited to the obstructed retinal vein and its surrounding tissues in the eyes with BRVOME. The eyes with BRVOME even showed an increase in MBR after IVB, particularly in the artery, although we could not confirm the significance of the difference statistically. If such an increase occurs, it is likely to be part of retinal autoregulation, as a compensatory increase in arterial flow rate to maintain retinal circulation. We believe that this is because in eyes with BRVOME, the retinal vessels are less damaged than in eyes with DME. Most studies of DR have noted upregulation of inducible nitric oxide synthase, ${ }^{35,36}$ with subsequent capillary degeneration, pericyte loss and permeability. ${ }^{37,38}$ Though the status of ocular blood flow in DR is still the subject of debate, ${ }^{39,40} \mathrm{CDI}$ and laser Doppler flowmetry have revealed that the velocity of blood flow in the ophthalmic artery and choroidal blood flow both decrease in eyes with DR. ${ }^{41,42}$ We believe that retinal autoregulation may be impaired in patients with DR and, furthermore, that the additional decrease in retinal circulation caused by IVB leads to an acceleration of the original chronic ischemia in eyes with DR, explaining the appearance of macular ischemia after IVB in patients with underlying diseases such as diabetes. ${ }^{14,15} \mathrm{Cau}-$ tion is therefore indicated when administering anti-VEGF antibodies, including bevacizumab, to DR patients. Even in eyes with BRVOME, although IVB can lead to a temporary reduction of the condition, we cannot exclude the possibility that IVB may also cause an adverse reduction in ocular circulation, particularly in the choroid. Thus, follow-up care in patients undergoing IVB should include LSFG examinations of ocular blood circulation, in addition to standard examinations of retinal structure and function.

It is difficult to make a prognosis on the structure and function of eyes with macular edema after IVB, especially for eyes with DME. Several biochemical mechanisms may contribute to the vascular disruptions that characterize DR and DME ${ }^{43}$ The pathogenesis of DME is still unclear but is thought to have several clinical aspects, including inflammation, disruption of the capillary barrier, and dysfunction of the retinal pigment epithelium. In our study, pre-IVB MBR in the ONH was significantly correlated with post-IVB FT of eyes with DME, a result indicating that IVB is not effective for patients with DME and low MBR. We believe that MBR of the $\mathrm{ONH}$ can be regarded as a clinically reliable preinterventional parameter, and that the predictive value of pre-IVB 
MBR may prove to be of importance, especially because LSFG measurements of MBR in the ONH have been reported to be highly reproducible. ${ }^{44}$ In fact, IVB is not always fully effective in reducing DME, and the pathogenesis of DME may include an IVB-sensitive mechanism related to vascular hyperpermeability (elevated MBR) and a non-IVB-sensitive mechanism, possibly related to impairment of the retinal pigment epithelium. Thus, we believe that the pathogenesis of DME may depend not only on VEGF, but also on other mechanisms suppressed by corticosteroids, as intravitreal injection of triamcinolone acetonide showed better results than IVB in reducing DME and improving BCVA. ${ }^{45}$ There are also reports showing that BRVOME is closely related to intraocular levels of cytokines such as macrophage inflammatory protein- $1 \beta$ and interleukin- 6 but not of VEGF. ${ }^{46,47}$

Our study was limited by a small sample size, the exclusion of types of macular edema besides BRVOME and DME, the restriction of the data to 1 month after IVB, and by the fact that characteristics were not matched between the two groups. We were also not able to find more than a weak connection between visual acuity and MBR. Nevertheless, we believe our results show that in eyes with BRVOME, IVB is currently a good choice to aid in recovery of FT and visual acuity, without a concomitant decrease in retinal blood flow, at least until such time as other antibodies are ready for clinical use. Furthermore, we are the first to report that pre-IVB MBR is significantly correlated with post-IVB FT in patients with DME, indicating the possible existence of VEGF- and MBR-dependent DME.

In conclusion, we found that in patients with BRVOME, there was no significant change in MBR in the retinal artery, retinal vein, or ONH. In patients with DME, MBR in all measured areas decreased significantly. Furthermore, preIVB MBR was significantly correlated with post-IVB FT in patients with DME, but there was no such correlation in patients with BRVOME. Higher pre-IVB MBR in these patients was an indicator of lower post-IVB FT. Measuring MBR with LSFG, therefore, has the potential to serve as a noninvasive and objective biomarker to help clinicians determine the value of IVB treatments for patients with DME. The focus of further investigation should be a determination of MBR relationship to the mechanism behind IVB-induced reduction of DME and BRVOME.

\section{Author contributions}

$\mathrm{HK}$ and $\mathrm{TN}$ were responsible for the design and conduct of the study. FN, HK, NA, KO, YS, and MY were responsible for the collection, management, analysis, and interpretation of the data. HK and TN were responsible for the preparation, review, and approval of the manuscript. All authors contributed toward data analysis, drafting and revising the paper and agree to be accountable for all aspects of the work.

\section{Disclosure}

This paper was partially presented at the 27th Annual Meeting of the Japanese Society for Ocular Circulation, Kobe, Japan, 2010. This paper was supported in part by JST grant, JSPS KAKENHI Grant-in-Aid for Scientific Research (B) (T.N. 26293372), for Scientific Research (C) (H.K. 26462629), and for Exploratory Research (T.N. 26670751). The authors report no conflicts of interest in this work.

\section{References}

1. Argon laser photocoagulation for macular edema in branch vein occlusion. The Branch Vein Occlusion Study Group. Am J Ophthalmol. 1984; 98(3):271-282.

2. Ferris FL 3rd, Patz A. Macular edema: a major complication of diabetic retinopathy. Trans New Orleans Acad Ophthalmol. 1983;31: 307-316.

3. Gutman FA, Zegarra H. Macular edema secondary to occlusion of the retinal veins. Surv Ophthalmol. 1984;28 Suppl:462-470.

4. Sigelman J. Diabetic macular edema in juvenile- and adult-onset diabetes. Am J Ophthalmol. 1980;90(3):287-296.

5. Yilmaz T, Cordero-Coma M. Use of bevacizumab for macular edema secondary to branch retinal vein occlusion: a systematic review. Graefes Arch Clin Exp Ophthalmol. 2012;250(6):787-793.

6. Kang HM, Chung EJ, Kim YM, Koh HJ. Spectral-domain optical coherence tomography (SD-OCT) patterns and response to intravitreal bevacizumab therapy in macular edema associated with branch retinal vein occlusion. Graefes Arch Clin Exp Ophthalmol. 2013;251(2): 501-508.

7. Shimura M, Yasuda K, Yasuda M, Nakazawa T. Visual outcome after intravitreal bevacizumab depends on the optical coherence tomographic patterns of patients with diffuse diabetic macular edema. Retina. 2013; 33(4):740-747.

8. Solaiman KA, Diab MM, Dabour SA. Repeated intravitreal bevacizumab injection with and without macular grid photocoagulation for treatment of diffuse diabetic macular edema. Retina. 2013;33(8):1623-1629.

9. Siegel RA, Dreznik A, Mimouni K, Bor E, Weinberger D, Bourla DH. Intravitreal bevacizumab treatment for macular edema due to branch retinal vein occlusion in a clinical setting. Curr Eye Res. 2012;37(9): 823-829.

10. Hanada N, Iijima H, Sakurada Y, Imasawa M. Recurrence of macular edema associated with branch retinal vein occlusion after intravitreal bevacizumab. Jpn J Ophthalmol. 2012;56(2):165-174.

11. Gulkilik G, Taskapili M, Kocabora S, Muftuoglu G, Demirci G. Intravitreal bevacizumab for persistent macular edema with proliferative diabetic retinopathy. Int Ophthalmol. 2010;30(6):697-702.

12. Hosseini H, Lotfi M, Esfahani MH, et al. Effect of intravitreal bevacizumab on retrobulbar blood flow in injected and uninjected fellow eyes of patients with neovascular age-related macular degeneration. Retina. 2012;32(5):967-971.

13. Matsuyama K, Ogata N, Matsuoka M, Wada M, TakahashiK, Nishimura T. Plasma levels of vascular endothelial growth factor and pigment epithelium-derived factor before and after intravitreal injection of bevacizumab. Br J Ophthalmol. 2010;94(9):1215-1218.

14. Shimura M, Yasuda K. Macular ischaemia after intravitreal bevacizumab injection in patients with central retinal vein occlusion and a history of diabetes and vascular disease. Br J Ophthalmol. 2010;94(3): 381-383.

15. Huang ZL, Lin KH, Lee YC, Sheu MM, Tsai RK. Acute vision loss after intravitreal injection of bevacizumab (avastin) associated with ocular ischemic syndrome. Ophthalmologica. 2010;224(2):86-89. 
16. Yoshida Y, Sugiyama T, Utsunomiya K, Ogura Y, Ikeda T. A pilot study for the effects of donepezil therapy on cerebral and optic nerve head blood flow, visual field defect in normal-tension glaucoma. J Ocul Pharmacol Ther. 2010;26(2):187-192.

17. Sugiyama T, Kojima S, Ishida O, Ikeda T. Changes in optic nerve head blood flow induced by the combined therapy of latanoprost and beta blockers. Acta Ophthalmol. 2009;87(7):797-800.

18. Takahashi H, Sugiyama T, Tokushige H, et al. Comparison of CCDequipped laser speckle flowgraphy with hydrogen gas clearance method in the measurement of optic nerve head microcirculation in rabbits. Exp Eye Res. 2013;108:10-15.

19. Wang L, Cull GA, Piper C, Burgoyne CF, Fortune B. Anterior and posterior optic nerve head blood flow in nonhuman primate experimental glaucoma model measured by laser speckle imaging technique and microsphere method. Invest Ophthalmol Vis Sci. 2012;53(13): 8303-8309.

20. Nagahara M, Tamaki Y, Araie M, Fujii H. Real-time blood velocity measurements in human retinal vein using the laser speckle phenomenon. Jpn J Ophthalmol. 1999;43(3):186-195.

21. Nagahara M, Tamaki Y, Tomidokoro A, Araie M. In vivo measurement of blood velocity in human major retinal vessels using the laser speckle method. Invest Ophthalmol Vis Sci. 2011;52(1):87-92.

22. Aizawa N, Kunikata H, Yokoyama Y, Nakazawa T. Correlation between optic disc microcirculation in glaucoma measured with laser speckle flowgraphy and fluorescein angiography, and the correlation with mean deviation. Clin Experiment Ophthalmol. 2014;42(3):293-294.

23. Yokoyama Y, Aizawa N, Chiba N, et al. Significant correlations between optic nerve head microcirculation and visual field defects and nerve fiber layer loss in glaucoma patients with myopic glaucomatous disk. Clin Ophthalmol. 2011;5:1721-1727.

24. Chiba N, Omodaka K, Yokoyama Y, et al. Association between optic nerve blood flow and objective examinations in glaucoma patients with generalized enlargement disc type. Clin Ophthalmol. 2011;5:1549-1556.

25. Sugiyama T, Araie M, Riva CE, Schmetterer L, Orgul S. Use of laser speckle flowgraphy in ocular blood flow research. Acta Ophthalmol. 2010;88(7):723-729.

26. Fabick MM. Ethical considerations for research on human subjects Plast Surg Nurs. 1995;15(4):225-227, 231.

27. Enserink M. Bioethics. Helsinki's new clinical rules: fewer placebos, more disclosure. Science. 2000;290(5491):418-419.

28. Forte R, Cennamo GL, Finelli M, et al. Intravitreal bevacizumab vs intravitreal triamcinolone combined with macular laser grid for diffuse diabetic macular oedema. Eye (Lond). 2010;24(8):1325-1330.

29. Arevalo JF, Sanchez JG, Wu L, et al; Pan-American Collaborative Retina Study Group. Primary intravitreal bevacizumab for diffuse diabetic macular edema: the Pan-American Collaborative Retina Study Group at 24 months. Ophthalmology. 2009;116(8):1488-1497, 1497.e1.

30. Paccola L, Costa RA, Folgosa MS, Barbosa JC, Scott IU, Jorge R. Intravitreal triamcinolone versus bevacizumab for treatment of refractory diabetic macular oedema (IBEME study). Br J Ophthalmol. 2008;92(1): 76-80.

31. Bonnin P, Pournaras JA, Lazrak Z, et al. Ultrasound assessment of short-term ocular vascular effects of intravitreal injection of bevacizumab (Avastin ${ }^{\circledR}$ ) in neovascular age-related macular degeneration. Acta Ophthalmol. 2010;88(6):641-645.

Clinical Ophthalmology

\section{Publish your work in this journal}

Clinical Ophthalmology is an international, peer-reviewed journal covering all subspecialties within ophthalmology. Key topics include: Optometry; Visual science; Pharmacology and drug therapy in eye diseases; Basic Sciences; Primary and Secondary eye care; Patient Safety and Quality of Care Improvements. This journal is indexed on Submit your manuscript here: http://www.dovepress.com/clinical-ophthalmology-journal
32. Okuno T, Sugiyama T, Kohyama M, Kojima S, Oku H, Ikeda T. Ocular blood flow changes after dynamic exercise in humans. Eye (Lond). 2006; 20(7):796-800.

33. Shiga Y, Shimura M, Asano T, Tsuda S, Yokoyama Y, Aizawa N, Omodaka $\mathrm{K}$, et al. The influence of posture change on ocular blood flow in normal subjects, measured by laser speckle flowgraphy. Curr Eye Res. 2013;38(6):691-698.

34. Isono H, Kishi S, Kimura Y, Hagiwara N, Konishi N, Fujii H. Observation of choroidal circulation using index of erythrocytic velocity. Arch Ophthalmol. 2003;121(2):225-231.

35. Carmo A, Cunha-Vaz JG, Carvalho AP, Lopes MC. Nitric oxide synthase activity in retinas from non-insulin-dependent diabetic GotoKakizaki rats: correlation with blood-retinal barrier permeability. Nitric Oxide. 2000;4(6):590-596.

36. Abu El-Asrar AM, Desmet S, Meersschaert A, Dralands L, Missotten L, Geboes K. Expression of the inducible isoform of nitric oxide synthase in the retinas of human subjects with diabetes mellitus. Am J Ophthalmol. 2001;132(4):551-556.

37. Zheng L, Du Y, Miller C, et al. Critical role of inducible nitric oxide synthase in degeneration of retinal capillaries in mice with streptozotocininduced diabetes. Diabetologia. 2007;50(9):1987-1996.

38. Leal EC, Manivannan A, Hosoya K, et al. Inducible nitric oxide synthase isoform is a key mediator of leukostasis and blood-retinal barrier breakdown in diabetic retinopathy. Invest Ophthalmol Vis Sci. 2007; 48(11):5257-5265.

39. Grunwald JE, Brucker AJ, Grunwald SE, Riva CE. Retinal hemodynamics in proliferative diabetic retinopathy. A laser Doppler velocimetry study. Invest Ophthalmol Vis Sci. 1993;34(1):66-71.

40. Patel V, Rassam S, Newsom R, Wiek J, Kohner E. Retinal blood flow in diabetic retinopathy. BMJ. 1992;305(6855):678-683.

41. Gracner T. Ocular blood flow velocity determined by color Doppler imaging in diabetic retinopathy. Ophthalmologica. 2004;218(4):237-242.

42. Nagaoka T, Kitaya N, Sugawara R, et al. Alteration of choroidal circulation in the foveal region in patients with type 2 diabetes. $\mathrm{Br} J$ Ophthalmol. 2004;88(8):1060-1063.

43. Ciulla TA, Amador AG, Zinman B. Diabetic retinopathy and diabetic macular edema: pathophysiology, screening, and novel therapies. Diabetes Care. 2003;26(9):2653-2664.

44. Aizawa N, Yokoyama Y, Chiba N, et al. Reproducibility of retinal circulation measurements obtained using laser speckle flowgraphy-NAVI in patients with glaucoma. Clin Ophthalmol. 2011;5:1171-1176.

45. Shimura M, Nakazawa T, Yasuda K, et al. Comparative therapy evaluation of intravitreal bevacizumab and triamcinolone acetonide on persistent diffuse diabetic macular edema. Am J Ophthalmol. 2008;145(5): 854-861.

46. Shimura M, Nakazawa T, Yasuda K, Kunikata H, Shiono T, Nishida K. Visual prognosis and vitreous cytokine levels after arteriovenous sheathotomy in branch retinal vein occlusion associated with macular oedema. Acta Ophthalmol. 2008;86(4):377-384.

47. Kunikata H, Shimura M, Nakazawa T, et al. Chemokines in aqueous humour before and after intravitreal triamcinolone acetonide in eyes with macular oedema associated with branch retinal vein occlusion. Acta Ophthalmol. 2012;90(2):162-167.

PubMed Central and CAS, and is the official journal of The Society of Clinical Ophthalmology (SCO). The manuscript management system is completely online and includes a very quick and fair peer-review system, which is all easy to use. Visit http://www.dovepress.com/ testimonials.php to read real quotes from published authors.

\section{Dovepress}

